Sobre María Laffitte y la Real Academia Sevillana de Buenas Letras

Begoña Barrera López

Universidad de Sevilla 



\title{
Sobre María Laffitte y la Real Academia Sevillana de Buenas Letras
}

\section{About Maria Laffitte and Real Academia Sevillana de Buenas Letras}

\author{
Begoña Barrera López \\ Universidad de Sevilla \\ begobarlop@gmail.com \\ Recibido: 18 de enero de 2014 \\ Aceptado: 19 de marzo de 2014
}

\begin{abstract}
Resumen
María Laffitte y Pérez del Pulgar, escritora y crítica de arte, fue recibida como Académico Correspondiente de la Academia Sevillana de Buenas Letras el 10 de mayo de 1957 con su discurso Aquella y esta Sevilla. El contenido del mismo, las circunstancias del evento, así como su posterior relación con la institución son recogidos desigualmente por los documentos conservados en el archivo de la Academia. La revisión y confrontación de este material y de las fuentes periodísticas permite conocer cómo fue la relación de la escritora con el mundo intelectual sevillano e ilustrar el modo de pensar y de actuar de María Laffitte.
\end{abstract}

Palabras clave: María Laffitte; Real Academia Sevillana de Buenas Letras; Sevilla; Discurso; Progreso; Evolución.

\begin{abstract}
María Laffitte y Pérez del Pulgar, writer and art critic, was welcomed as academic of Real Academia Sevillana de Buenas Letras [Royal Sevillian Academy of Belles Lettres] the 10th of May 1957 with her conference That and This Seville. The content and the circumstances of the event, as well as her connexion with the institution has been unequally reflected in the documents of the Academy's archive. The review and comparison of this material, and the journalists' sources allows to understand how was the relation between the academic and the intellectual circle, and this shows the Marías way of thinking and act.
\end{abstract}

Key words: María Laffitte; Royal Sevillian Academy of Belles Lettres; Conference; Progress; Evolution.

Para citar este artículo: Barrera López, Begoña (2014). Sobre María Laffitte y la Real Academia Sevillana de Buenas Letras. Revista de Humanidades, n. 21, p. 31-50, ISSN 1130-5029. 
María Laffitte nació en Sevilla el 15 de agosto de 1902. Hasta sus veinte años vivirá en esta ciudad, sobreprotegida en el interior de grandes casas sevillanas que configurarán para ella un mundo apartado de la realidad exterior. A partir de su matrimonio con el conde de Campo Alange (el gran ausente de las memorias de María, al que apenas nombra y cuando lo hace jamás es por su nombre) se trasladará a vivir a Madrid. Sobre sus primeros años en Sevilla, la autora recuerda en sus memorias que:

El mundo de mi juventud -como el de mi niñez- fue angosto, cerrado y fuertemente vinculado a una tradición que por su lenta evolución y por nuestra ignorancia en materia de evolucionismo, nos daba la sensación de inmovilismo histórico (1983:15).

Durante los años treinta y hasta el final de la Guerra Civil, el matrimonio vivió en Paris, donde Laffitte tomó contacto con la cultura y el arte contemporáneo. El vivo interés que despertará en ella la pintura moderna se tradujo en su primer libro, dedicado a la pintora cubista María Blanchard (1944). Este mismo año entró a formar parte de la Academia Breve de Crítica de Arte, dirigida por Eugenio d'Ors, que celebraba periódicamente exposiciones en apoyo al arte español contemporáneo. «Empecé a enfrentarme con la incomprensión de la gente, -afirma la escritora-con su atraso histórico cultural. [...] El pintor que seguía la línea actual era, en España, un incomprendido. Sin establecer todavía de forma consciente un paralelismo entre la situación del pintor y la situación de la mujer de aquel momento, llegué a encontrar cierta similitud» (1983: 62). Comenzó entonces a madurar un proyecto para reivindicar los derechos de la mujer y criticar su situación social y cultural. En 1948 publicará el polémico La guerra secreta de los sexos en la editorial de la Revista de Occidente. Tres elecciones, el tema de la obra, su título y la decisión de publicarlo en la editorial de José Ortega y Gasset debilitarán extremadamente su relación con d'Ors y su círculo intelectual: «Te has pasado al enemigo», «No haré nada para que se venda este libro» fueron, según Laffitte, las palabras que le dirigió el erudito (1983: 73).

En los años cincuenta, un viaje a Estados Unidos le reafirmó en su interés por el arte contemporáneo más vanguardista (cine, fotografía....). Esta inclinación aparecerá siempre vinculada y potenciada por su fascinación por los temas científicos. Ciertamente, toda su vida intelectual giró en torno a tres vectores sobre los cuales se construye su pensamiento: cultura visual, ciencia y mujer. Desde el convencimiento de que el progreso científico habría de ser guía y ejemplo para la evolución social y cultural, la escritora defendió en sus siguientes obras el progreso, entendido como mejora, de las artes plásticas (De Altamira a Hollywood. Metamorfosis del Arte, 1953) y de la situación de la mujer (La mujer como mito y como ser humano, 1961; La mujer en España. 100 años de su historia, 1964; y Concepción Arenal. 1820-1893. Estudio biográfico documental, 1973). Este interés se consolida con la fundación en 1960 del Seminario de Estudios Sociológicos de la Mujer cuyas 
integrantes manifestaban una «honda preocupación por los problemas sociales» (1968: 12) y se proponían «despertar las conciencias especialmente somnolientas de las mujeres españolas» (1983: 122).

Las obras de ensayo, crítica e investigación se alternaron en la producción de Laffitte con otro género, el autobiográfico. Tradicionalmente la (escasa) bibliografía dedicada a su escritura ha reconocido la existencia de dos obras de este tipo, $M i$ niñez y su mundo de 1956, considerada como autobiografía de infancia y $M i$ atardecer entre dos mundos, de 1983, catalogada como autobiografía testimonial (Masanet, 1998: 50). Fue a raíz de la publicación del primero de estos libros cuando la Real Academia Sevillana de Buenas Letras la propuso como "académico» correspondiente. Con una fuerte carga literaria, este libro narra episodios de su infancia en Sevilla y recuerdos de casas de patios, cancelas de hierro, paseos por la huerta de Los Remedios y modistos de París que diseñaban para su madre. Si incurrir en tipismos ni dar tampoco un barniz modernizador a sus palabras (lo cual hubiera sido tan fácil como poco honesto para ella), relata tanto el inicio de su devoción cristiana y el cariño con el que fue criada, como la insistente y frustrante prohibición de ir al colegio. Ciertamente, la lectura le fue habitualmente censurada por su madre, que consideraba que «las lecturas son muy peligrosas» (1990: 133). Sea como fuere, la publicación de estos recuerdos infantiles debió calar hondo en los académicos sevillanos. La autora narra excepcionalmente en sus memorias sus impresiones acerca del nombramiento:

Dejándose llevar por un impulso generoso, saltándose a la torera -tratándose de Sevilla el símil es doblemente oportuno- el protocolo, me hicieron un recibimiento en sesión pública y solemne, con el mismo ceremonial usado para recibir a los académicos de número. En aquellos momentos era presidente de la Academia don José Sebastián y Bandarán. Fue una excepción que agradecí en todo su valor. Por entonces no había en la Academia más que una mujer: doña Blanca de los Ríos, nacida también en Sevilla y por rara casualidad el 15 de agosto, como yo, cuando la Virgen de los Reyes recorría las calles en procesión.

De paso diré que la cuestión de las Academias -provincianas o no-, y a las que tanto respeto tengo, ni me ha hecho nunca soñar ni menos aún me ha quitado el sueño (1983: 97).

La Real Academia Sevillana de Buenas Letras había sido fundada a mediados del siglo XVIII con vocación católica ilustrada. Desde sus inicios su vinculación a la Real Academia de la Historia marcó el interés historicista de las investigaciones que sus miembros realizaban, matizado por la preferencia de temas andaluces o sevillanos y de historia eclesiástica. Más tarde, se introdujeron progresivamente los temas filológicos y literarios, sociales y científicos, aspirando así a la interdisciplinariedad. A finales del siglo XVIII y principios del XIX sufrió una etapa de decaimiento a causa de la invasión francesa, que provocó el desmantelamiento de su sede y la dispersión 
de sus miembros. En 1820 se reanudaron las sesiones y se inició una nueva andadura que continuó con la voluntad de contribuir al conocimiento histórico y antropológico de Andalucía y de su capital. Desde su fundación y por disposición estatutaria, ha contado con una nómina de treinta Académicos de Número. Puede, asimismo, nombrar Académicos de Honor a personas de muy relevantes méritos, y Académicos Correspondientes a aquellos que residan fuera de Sevilla y estén vinculados a la Academia por su labor investigadora y cultural. A esta última categoría perteneció el nombramiento de María Laffitte en 1957 que, pese a ser nombrada Correspondiente, hizo un lectura «en sesión pública y solemne» con motivo de su entrada en la institución del mismo modo que acostumbraban a hacer los Académicos de Número entrantes.

En la amplia obra bibliográfica de María Laffitte solo aparece referida su vinculación con la Academia sevillana dos veces. La primera, en su propio discurso de entrada publicado el mismo año de 1957 por la institución tal y como se hacía con todas la conferencias de entrada. La segunda, en el último libro de memorias de 1983; esta referencia corresponde a los tres párrafos arriba incluidos. La escasez de alusiones en el ámbito bibliográfico es paralela a la limitación de datos que se encuentran en las fuentes del archivo de la Academia. Los documentos consultados en este archivo han sido el discurso de entrada y las actas de las juntas y sesiones públicas de los años 1951 hasta 1988 que se encuentran divididas en dos tomos: 1951-1971 el primero y 1971-1988 el segundo. Adicionalmente, se ha analizado la información que recoge el Boletín Minervae Baeticae de la Academia, desde 1975 hasta 1987, ${ }^{1}$ así como la mención a la entrada de la escritora en la institución que incluye la edición sevillana del diario $A B C$. En relación a las actas, hay que señalar que su información no se recoge en ninguna base de datos, ni informática ni manuscrita, por lo que los volúmenes se encuentran guardados sin ningún criterio cronológico. Por su parte, del Boletín solo se han digitalizados los números publicados a partir de 1975 y que corresponden a la «nueva época».

Tanto el título como el contenido del discurso de entrada a la Academia de Laffitte hacen referencia a la ciudad donde nació y vivió hasta los veinte años. La elección de este motivo debió parecerle la más adecuada a la escritora, que conocía la preferencia de la institución académica por las disertaciones y los estudios de temas eminentemente sevillanos. No obstante, sus palabras cuentan con un contenido autobiográfico en el que las referencias a la ciudad como motivo real y metafórico le permiten reflexionar sobre sus cambios vitales. Así, al comienzo del texto y a modo de introducción (pp. 1-9), Laffitte expone la intenciones de la conferencia que va pronunciar y descarta que sus palabras respondan a la nostalgia por el pasado:

1 Este margen temporal está delimitado por la digitalización de la publicación a partir del número de 1975, y por el fallecimiento de María Laffitte, que se produce en el 9 de julio de 1986 y que, de haber tenido alguna repercusión en los contenidos del boletín (se tratará más adelante esta ausencia de alusiones a su fallecimiento) habría sido en el número de 1987. 
Para mí [...] existen dos Sevillas: la que actuó de continente en el mundo de mi niñez $-\mathrm{y}$ hasta de mis primeros veinte años-y ésta con la que me enfrento ahora, ya en plena madurez, desde un mundo enteramente distinto [...] Me limitaré a evocar ciertos aspectos de que lo llamo «aquella Sevilla» y a comentar brevemente la Sevilla de hoy (1957:7-8).

\section{$[\ldots]$}

¿Nostalgia? En todo caso no soy propensa a ella y no tengo por costumbre volver la vista atrás. El pasado -autobiográfico o histórico- no me interesa más que en la medida de lección (1957: 9).

El texto editado que se ha conservado en el archivo de la Academia sevillana consta de 36 páginas y puede dividirse en tres partes. En la primera, y tras la introducción que se ha señalado, la escritora defiende su particular visión sobre el progreso social y cultural; en la segunda, traza un recorrido imaginario por Sevilla ejemplificando el cambio que ha sufrido la ciudad y sus ciudadanos; en la tercera, alude a los beneficios y perjuicios que trae consigo la modernización y el progreso de la sociedad. Así pues, en la primera parte del discurso (pp. 9-14) la autora va enfocando sus palabras hacia el tratamiento de uno de los temas más recurrentes en sus obras y que arriba ya se ha citado: la evolución científica y humana. Quiere posicionarse en una idea que de partida evidencie su pensamiento progresista respecto a las transformaciones sociales, una idea que irá retomando a lo largo del texto pero que le ayuda a coger impulso y a presentarse ante el auditorio como una persona versada en temas científicos. De hecho, siguiendo las referencias de sus libros, se puede apreciar cómo Laffitte conocía las teorías científicas de Pierre Teilhard de Chardin, ${ }^{2}$ Julian Huxley, Frederik J. J. Buytendijk, Lucien Cuénot, André Tétry o Jean Rostand entre otros. Ella misma señala que fue durante «los primeros cincuenta» cuando se entregó de forma más constante a los textos sobre «evolución biológica» (1983: 178).

De entre todos los autores citados y recogidos en sus libros, fue con Teilhard de Chardin y con teoría del evolucionismo finalista con el que la escritora sintió una

2 Pierre Teilhard de Chardin (1881-1955) fue un científico jesuita, paleontólogo y filósofo francés. Sus obras, defensoras de un evolucionismo teleológico, fueron consideradas fuera de toda ortodoxia por Iglesia, que censuró su conocido trabajo El Fenómeno humano, el cual solo pudo ser publicado después de su muerte. Su novedosa percepción de un cosmos en evolución ("cosmogénesis"), le llevó a alejarse de los presupuestos materialistas del darwinismo y de las interpretaciones mecanicistas del cosmos, ya que Teilhard defendía que tanto la materia como el pensamiento se encontraban insertos en el proceso evolutivo del cosmos. Su concepto de «noosfera», tomado de Vladimir Ivanovinch Vernadsky, define a aquel espacio virtual en el que nacen y se desarrollan todos los fenómenos del pensamiento y la inteligencia, es el espacio de la evolución de la conciencia universal, al igual que la biosfera es el ámbito de evolución biológica. Vid. Cuénot, C., (1966) Teilhard de Chardin, Barcelona, Labor; Makinistian, A., (2004) Desarrollo histórico de las ideas y teorías evolucionistas. Zaragoza, Prensas Universitarias de Zaragoza; y Pérez de Laborda, A., (2001) La filosofía de Pierre Teilhard de Chardin: la emergencia de un pensamiento transfigurado. Madrid, Encuentro Ediciones. 
mayor vinculación intelectual, declarando que la lectura de El fenómeno humano ensanchó prodigiosamente sus ideas sobre la evolución biológica. ${ }^{3}$ Laffitte apunta una de las ideas que se repiten con más frecuencia a propósito del paleontólogo, y es la de que éste tuvo la ambición de ver el complejo fenómeno humano en su contexto cósmico uniendo religión y ciencia (1983: 180). Hacia mediados de los años cincuenta, después del fallecimiento del jesuita francés, sus ideas tuvieron un particular impacto especialmente en científicos de convicciones católicas. En las décadas siguientes a su muerte, los más decididos defensores de sus ideas fueron los franceses Jean Piveteau y Claude Cuénot y los españoles Miguel Crusafont Pairó, Emiliano Aguirre y Bermudo Meléndez (Makinistian, 2004: 249). María Laffitte, por su parte, no sólo conoció a los cuatro primeros, sino que les invitó a formar parte de un ciclo de actividades sobre la evolución en el Ateneo de Madrid cuando ella ejercía como vicepresidenta del mismo (1962-1968). ${ }^{4}$

Volviendo al discurso de entrada en la Academia sevillana, en esta primera parte la referencia a la ciudad no aparece más que en dos ocasiones (p. 11, 1. 22 y p. 13 1. 7), y solo como modo de reconducir sus palabras hacia el tema central. Antes de ver los ejemplos, conviene examinar la idea de progreso que ella incluye. La escritora afirma:

Pero si por nostalgia se entiende el pesar que causa la falta de algún bien perdido, yo diría que siento con frecuencia la nostalgia del futuro, $[\ldots]$ porque, en contra de lo que muchos piensan, creo en el «progreso indefinido», que, para mí, está lejos de ser un «mito» ligado a la época de «la Ilustración», y, por tanto, algo viejo y caduco (1957: 9).

Laffitte cree, siguiendo a Teilhard de Chardin y citándole, que la «humanidad progresa y perfecciona sin posible retorno». Los cambios que se habían ido sucediendo hasta entonces, el «fabuloso progreso técnico de los últimos treinta años» solo puede ser valorado positivamente. De ahí que reconozca: «no practico, por consiguiente, el misoneísmo, y no pertenezco al grupo de los que emiten agrios juicios de disconformidad a cada innovación, por el solo hecho de serlo» (1957: 11). Desde una perspectiva católica, reconoce la importancia de la espiritualidad y a la vez rechaza el pensamiento fijista y mítico, al que considera atrasado y anacrónico, apostando por lo que ella denomina la «mente científica» propia del siglo XX. La

3 Originalmente publicado en francés como (1955) Le phenomène humain, Paris, Editions du Seuil. La primera edición española es (1963) El fenómeno humano, Madrid, Taurus Ediciones.

4 Entre propuestas a la Junta Directiva del Ateneo estuvieron las actividades de divulgación científicas relacionadas con el evolucionismo. Junto con Emiliano Aguirre, eligió como tema para unas conferencias La evolución del hombre, desde la biología hasta la sociología. En el mismo curso de 1963-64, se desarrolla otro ciclo titulado Teilhard de Chardin y compuesto igualmente de conferencias y seminarios. Aunque en las Memorias de Actividades de la institución no figure el director de estas actividades, muy probablemente estuvieran, si no dirigidas, auspiciadas por Laffitte y Aguirre. (M. A., p. 76-82). 
voluntad de progreso - y esto es fundamental para el pensamiento de Laffitte- no procede del apoyo a ninguna ideología política o grupo social, sino que es una apuesta individual, reflexionada, y deducida de la teilhardiana idea de la evolución como algo consustancial a este mundo, inevitable y deseable. Por ello aclara: «Soy lógicamente progresista. Y soy progresista porque pienso que de este modo sigo la misma dirección que la naturaleza, y que en su forma de proceder tiene que residir, necesariamente, la verdad» (1983: 170).

Al ser una concepción global, esta noción impregna todos sus escritos y proyectos, convirtiéndose en el elemento común a todas sus obras. De este modo, no es de extrañar que no exista un libro o un artículo suyo en el que no intervenga sustentando firmemente la idea de evolución. Ella misma lo reconoce:

Me refiero a la trayectoria de mi obra escrita, que a primera vista pudiera parecer heterogénea, falta de unidad, pero que, si se le presta mayor atención, se verá que sigue una misma línea: la evolución. Evolución de las artes visuales, evolución social de la mujer, evolución de mi propia vida... simultáneamente, mi interés por la evolución biológica, por la evolución social. Me atrae lo que se mueve, lo que avanza; su trayectoria. Me molestan los inmovilismos, el miedo al futuro, lo que, por pereza, va quedando atrás (1983: 109).

Retengamos un elemento de esta cita: «evolución de mi propia vida». Efectivamente, desde la escritura, ella interpretó su propia trayectoria como la evolución vital de un individuo dentro de un proceso global con el que quiere estar en armonía. Proceso que le permite, además, poder hablar en términos de presente y pasado, concretando ambas categorías vitales a partir de los cambios que ha percibido en el mundo exterior. Es decir, hablando de dos mundos, uno antiguo y otro moderno, por los que transita y mediante los cuales interpreta su propia vida. ${ }^{5}$ En el discurso ante la Academia sevillana, este recorrido le corresponde a la ciudad de Sevilla, que comparte un elemento común con la vida de la escritora: la evolución inevitable hacia un nuevo mundo y la permanencia de elementos del pasado en esta nueva época, lo cual permite equilibrar el contraste entre ambas etapas. Así, afirma que «entre aquella y esta Sevilla no solo hay que hablar de un cambio evidente de "época", sino de la entrada en una nueva era. No obstante, este pasado tiene todavía una forma de supervivencia: está "presente" en la mente de mis coetáneos» (1957: 13). Sobre esta permanencia de lo antiguo en lo moderno se volverá más tarde.

5 La importancia de este modo de concebir la propia biografía es clave desde una perspectiva de género, ya que históricamente la evolución vital de una mujer y sus distintas etapas habían estado marcadas por el régimen biológico y rara vez por los cambios que se producen en el mundo exterior, en la vida pública, en la esfera social. Por este motivo son bien destacables sus afirmaciones al respecto en 1983: «Suspendidos en el vacío, ignorando todavía lo que ha de venir en un futuro más o menos inmediato, mientras decimos adiós al mundo mágico en el que hemos vivido hasta ahora [...] Confieso que vivo "mi atardecer" bien equilibrada entre ambos mundos. Tengo raíces profundas en aquel y brotes tiernos y vigorosos en éste». 
La segunda parte del texto (pp. 14-36) Laffitte la dedica a realizar un recorrido imaginario por la ciudad para constatar los cambios a dos niveles, «su estructura física» y «su vida social, dando a la palabra social un amplio sentido humano» (1957: 14). Las referencias a los lugares que asocia a su niñez, como la huerta de los Remedios o la calle Mateos Gago, son las mismas que aparecen en sus primeras memorias (1953). Por ello resulta de más interés destacar los aspectos que la escritora toma como ejemplo del cambio que la ciudad ha sufrido en los últimos cincuenta años. Así, llama la atención sobre el concepto sevillano de vivienda, por el cual a principios de siglo de siglo hubiera sido impensable para una familia acomodada (como la suya) vivir en «casas de pisos», idea que a finales de los cincuenta ya había comenzado a desaparecer. Igualmente, ante el problema urbanístico y la falta de planificación que ella considera que ha sufrido el centro de la ciudad («su centro ha quedado mezquino [...] su trazado es inaprovechable y, en grandísima parte, también sus edificios»), ella afirma que "la única solución lógica parece ser la de dejar las cosas como están, olvidar el conflicto insoluble y crear, poco a poco, una nueva y moderna Sevilla, fuera del viejo recinto» (1957: 29).

No obstante, merece especial atención el énfasis que la escritora pone en la transformación de la mujer sevillana, a lo que dedica más comentarios y anécdotas que a ningún otro de los aspectos sociales. ${ }^{6}$ Sobre su atuendo, afirma que antes lo usual era el uso de la mantilla, la peina baja de carey, y el mantón de espuma para la mujer de pueblo. Laffitte relaciona la desaparición de estas costumbres con un fenómeno más general que denomina «pérdida del carácter local». Como anécdota, afirma que en el desaparecido teatro de San Fernando se celebraban dos espectáculos, uno en el escenario y otro en la sala, donde se producía un juego de miradas de hombre a mujer, de mujer a mujer, pero nunca de mujer a hombre, y donde el éxito de cada muchacha se juzgaba por el número de jóvenes que se reunía ante ella y delante del palco. Nunca en el patio de butacas, pues «por entonces una mujer no podía ocupar una butaca sin mengua de su posición social. Por la misma razón, no podía subir a una tranvía y solo en determinadas ocasiones a un coche de "punto"» (1957: 24-25). En esta Sevilla, la sustitución de aquellos palcos por filas de butacas equivale, para ella, a la desaparición de aquellos rituales sociales.

El crecimiento urbano acompaña a la renuncia voluntaria a las formas tradicionales de vida. Con tristeza, alude al tipismo, que según ella «ha sido ligado a la incomodidad y a la falta de higiene», añadiendo que:

Ciertamente que «lo viejo» resulta deprimente e incómodo, pero ¿por qué no renovarse dentro de la misma línea? Creo más bien que el sevillano empieza a estar saturado de azulejos, de mármoles y de hierros forjados y ahora desea

6 Véase en relación con esto el dato que recogen las actas sobre el público asistente y que se comenta más adelante. 
cosas distintas. Creo también que el concepto de lo «agradable» ha cambiado radicalmente (1957: 29-30).

La cuestión de si es posible renovarse dentro de la misma línea -dentro de la tradición- es una nota disonante respecto al cariz progresista que había tomado el discurso anteriormente. El apoyo a la renovación dentro de la tradición puramente española era el as del mundo cultural de entonces y, por supuesto, uno de los estandartes del grupo de críticos de arte más influyente del periodo franquista. Desde los más conservadores (como Manuel Abril o Fernando Jiménez Placer) hasta los más partidarios la apertura a las nuevas corrientes (Enrique Azcoaga, Rafael Santos Torroella y compañía), la necesidad de conservar cierta esencia española en la creación plástica es un tópico que se repite desde 1939 hasta finales de los años cincuenta como un mantra. ${ }^{7}$ En el caso de Laffitte, es muy escasa la aparición de este tópico. De hecho, si resulta urgente su recuperación como crítica de arte y ensayista es precisamente por no ajustarse a ninguna de las convenciones ni de los estereotipos que se fraguaron entonces sobre la crítica de arte. Su defensa del arte moderno, o de la mujer como artista en igualdad de condiciones que el varón, la sitúa al margen (nunca mejor dicho) del grupo de críticos oficiales.

No obstante, en las últimas páginas del discurso, la autora cambia el tono hacia un tinte más moderado. A propósito del arte, se pregunta de nuevo «¿Es que el arte popular está en trance de desaparición? ¿Participa Sevilla en el fenómeno general?». Y añade: «Claro está que, a medida que el arte popular desaparece, un "nuevo arte" va recogiendo, por decirlo así, las fuerzas ancestrales contenidas en él. Una nueva pintura nace en Sevilla. Yo he visto muestras excelentes y prometedoras» (1957:31-32). Defensora declarada del arte moderno, para resolver el difícil trance entre lo antiguo/popular y lo nuevo, recurre a la bien conocida táctica de hacer a lo nuevo heredero espiritual de lo antiguo.

No olvida en sus últimas frases hacer alusión a la importancia de conservar el patrimonio histórico sevillano, mención que debieron apreciar sin duda los miembros presentes de la Comisión Provincial de Monumentos Históricos y Artísticos, habituales asistentes desde los años cuarenta y hasta los ochenta a las sesiones de

$7 \quad$ La apuesta por el arte moderno (de primeras y segundas vanguardias) no fue una realidad hasta bien entrado los años cincuenta, y en gran parte debido al impulso de la primera Bienal Hispanoamericana de Arte organizada en Madrid en 1951. El régimen había comprendido la urgente necesidad de acercarse a ciertas tendencias artísticas, en boga por París y Nueva York en aquellos años, a fin de «normalizar» las apreciaciones que muchos intelectuales (de dentro como de fuera) tenían de la realidad cultural del país. De todas formas, es bien conocido que la voluntad del régimen no era modernizar el arte actual y contribuir a la difusión de los más avanzados, ni mucho menos, sino elaborar un eficaz aparato de propaganda política que, mediante una gran maquinaria mediática, contribuyera al pretendido lavado de cara del franquismo. Véase Marzo, J. L., (2006) Arte moderno y franquismo. Los orígenes de la vanguardia y de la política artística en España. Alojado en la plataforma www. soymenos.net. 
entrada de nuevos académicos, según recogen las actas de estos eventos. Cabría la lógica posibilidad de que la escritora, conociendo parte del público que iba a encontrar frente a sí en su lectura, conviniera la necesidad de dedicar (indirectamente) unas palabras a los miembros de esta comisión. Además, el lugar donde ella estaba haciendo su lectura de ingreso, el convento de la Merced, era la sede del Museo Provincial y el lugar, por tanto, donde los miembros de aquella comisión reunían las obras recabadas a los conventos desamortizados de la ciudad. Así pues, Laffitte defiende la

necesidad de protegerlas, de defenderlas de la incomprensión y la indiferencia de los demás [«las formas plásticas del pasado»] . A veces hay razones de orden práctico que invitan a destruirlas o a modificarlas. Pero el respeto a la obra estética triunfa y se habla de "monumento nacional", fórmula legal por la que las piedras aludidas son declaradas intocables (1957: 35).

Para concluir sus palabras, la escritora lanza una ambigua propuesta que sólo puede ser comprendida mediante la correcta interpretación del lenguaje que utiliza. Si antes se ha referido a las «formas plásticas del pasado» y a la necesidad de conservarlas, ahora reclama esta exigencia de protección para lo que llama «actitudes espirituales», preguntándose «¿por qué las actitudes espirituales, cuando son realmente bellas -como lo es, en grado superlativo, el concepto andaluz de la vida-, no han de ser defendidas, protegidas y "conservadas" recurriendo para ello a todos los medios?».

En una lectura superficial, parecería que lo que la escritora trata de insinuar es la exigencia de conservar los usos tradicionales y típicos de los sevillanos ante la amenaza de una perversa modernidad que podría destruirlo. Como se verá a continuación, esta fue la lectura oficial que se hizo de sus palabras. Sin embargo, al tener en cuenta cuál es el significado de la palabra «espíritu» para ella, una de las más utilizadas en sus libros y artículos, se descubre otra posible interpretación. Su concepto de «espíritu» es, de entrada, eminentemente laico, y en escasas ocasiones aparece ligado al ámbito religioso. Más bien, creo que Laffitte entiende por espíritu la psicología esencial de cualquier sexo, condición, o sociedad. Así, defiende la existencia de un espíritu femenino, oprimido y deformado por el masculino (adscribiéndose a un feminismo de corte claramente esencialista); un espíritu artístico, propio solo de los grandes creadores y que, en el caso de poseerlo, está por encima de la condición de su sexo; ${ }^{8}$ y un espíritu popular y social, determinado por los rasgos culturales que el contexto imprime en el individuo. ${ }^{9}$

8 Como es habitual en estos años, con la palabra «sexo» se manifiesta intuitivamente el concepto de identidad construida que a partir de los ochenta de denominará «género».

9 Véase la utilización del término «espíritu» en los siguientes ejemplos: La secreta guerra de los sexos (1948) y La mujer como mito y como ser humano (1961) para el primer caso. María Blanchard (1944) y «Meditación Estética» (1952), entre otros, para el segundo. Mi niñez y su mundo 
Si esto fuera así, lo que la escritora está reclamando no es una fosilización de las costumbres y de los hábitos que no permita una evolución de la sociedad sevillana. Ello sería completamente incoherente con su pensamiento. Más bien, cuando defiende en sus últimas frases que los poetas sevillanos deberían redactar un «Código de las esencias andaluzas» para "proteger de modo eficaz e inteligente esas "formas poéticas amenazadas"», ella parece estar aludiendo a la necesidad de no dejar que la modernidad arrase y elimine la memoria y los conceptos más esenciales de la vida andaluza. En sus dos libros de memorias, y siempre que pudo, dejó constancia de la unión que sentía con la naturaleza, «viviría siempre en el campo» afirmó a un periodista que la entrevistó (1957: 37). Esta unión con la naturaleza siempre la justificó por sus orígenes andaluces, por la vinculación con determinados tipos de paisajes que ella, como muchos, conservó siempre en la retina. «Después de tantos años de alejamiento de tierras andaluzas, el recuerdo o la vista del naranjo sigue produciéndome una emoción muy honda que, sin duda, tiene su raíz en aquella amistad de infancia que hubo entre el naranjo y yo», afirmaba (1956: 65).

Siguiendo esta idea, a lo que aludiría la escritora es a la necesidad de prevenirse de los excesos de la modernidad, una «etapa necesaria», como ella bien dice, pero también brutal, que en muchos casos ha pecado de excesiva y desmesurada. Ya en 1948 había aludido en La secreta guerra de los sexos al peligro del «maquinismo» que tiende a considerar que todo, hasta el proceso más natural que es el de fecundación de un hijo, puede ser tecnificado. No es entonces extraño que vuelva sobre este punto. Es más, se podría considerar este aspecto como otro de los temas ciertamente recurrentes sobre los que la autora va pensando en sus libros. Si, de un lado, defiende a ultranza el progreso y la evolución de las sociedades, por otro es consciente y previene de los excesos que muchas veces se cometen en esta etapa. Tampoco habría que olvidar que Laffitte y su marido habían pasado la década de los treinta viviendo intermitentemente en París, años en los que en Francia uno de los temas más tratados y polemizados es precisamente el de los usos, abusos y pérdidas (al fin y al cabo, las contradicciones) que ha traído la modernidad a la civilización europea.

Una vez vistos los puntos fundamentales del discurso, conviene contrastarlos con la información recogida en las actas correspondientes al día de su discurso. $\mathrm{La}$ redacción de este documento corre a cargo del secretario Juan Rodríguez Mateo (1888-1963) que, siguiendo la fórmula protocolaria, después de las presentaciones de los académicos y de hacer un breve referencia al público de la sala (del que se hablará más abajo), realiza un resumen de las palabras de la ponente. El entonces secretario era un poeta coriano del que se ha dicho que permaneció firme a la poesía tradicional, costumbrista y religiosa y que había demostrado devoción por el posromanticismo y el modernismo. Rodríguez Mateo era conocido en el círculo

(1956) para el tercero. 
sevillano por su trabajo literario, el cual le había valido para lograr el entonces importante «Premio Sánchez Bedoya» de poesía, que anualmente otorgaba la Real Academia Sevillana de Buenas Letras, con la composición titulada «Ala Virgen María en su original y eterna Pureza». El 17 de febrero de 1946 ingresaría como Académico de Número en la institución sevillana con el discurso La Copla y el Cante Popular en Andalucía, sustituyendo a Don Diego Angulo Laguna y siendo contestado por Don Rafael Laffón y Zambrano (1998: 172). Es precisamente con este último con quien mantiene una conversación, recogida y comentada por Pineda Novo, donde muestra el talante que había impreso en él los años posteriores a la Guerra Civil: «tuvo que acomodarse a la nueva España, surgida del 18 de Julio de 1936... Entonces cambia el rumbo de su poesía, se hace más patriótico, más religioso, sin perder su sentimiento popular, como me dijo Rafael Laffón, su fraternal amigo en El Ateneo y en la Real Academia, que, además añadió "Cuando llamaron a Juan ante el juez, él respondió: 'Yo no tengo más defensa que ésta: Tengo un confesor hace tiempo, el P. Manuel de la Virgen del Carmen, del convento del Santo Ángel, y no he tenido vinculación con la República" (citado en Pineda Novo, 2007).

Resulta significativa la elección de las ideas que se hace y el significado que se les otorga así como el lenguaje que se escoge para la expresarlas, utilizando términos que la escritora no emplea. En las actas se afirma que Laffitte

Comenzó destacando cómo la visión de Sevilla del que reside en ella difiere de quien vuelve a la ciudad tras años de prolongada ausencia, como en su caso, pues el primero no percibe en su totalidad las mudanzas que paulatinamente el tiempo va operando (LARASBL ${ }^{10}, 1951-1971$ : fol. 35v). [El subrayado es nuestro]

Es cierto las primeras palabras las dedica la ponente a hacer esta comparación («para el sevillano que no ha dejado de vivir en la hermosa ciudad del Betis, Sevilla es sólo una. [...] Para mí, en cambio, por circunstancias espaciales, existen dos Sevillas ...» [1957: 7]), sin embargo, la expresión «las mudanzas que paulatinamente el tiempo va operando» es una declaración que en el discurso no aparece. Sí son muy abundantes, en cambio, los términos «progreso», «evolución» y «cambio», que hacen referencia, con sentido positivo, a la transformación que ha sufrido la ciudad. Por algún motivo, el secretario ha optado por elegir la ambigua palabra «mudanzas», tal vez evitando incluir el matiz progresista que tiene el discurso de Laffitte, sobre todo en esta primera parte. La continuación del acta da fuerza a esta hipótesis: «La comparación de la panorámica que ofrece de la Sevilla de ayer con la realidad sevillana del presente, donde tantas cosas se han perdido, lleva a la disertante a hacer jugosas consideraciones» (LARASBL, 1951-1971: fol. 35v). Efectivamente, ni rastro de la intención de la escritora de defender la conveniencia del progreso, ningún indicio en las actas las numerosas afirmaciones la declaraban partidaria de la

10 Libro de Actas de la Real Academia de Buenas Letras de Sevilla. 
evolución social, no solo de Sevilla, sino de la humanidad. No obstante, sí aparecen en las actas literalmente recogidas sus últimas frases, las más conservadoras:

Dice: Cuando las piedras ilustres se ven amenazadas, se las salva declarándolas monumento nacional. Algo parecido debiera intentarse con el acervo espiritual. $\mathrm{Y}$ esto es urgente, porque las constantes del espíritu sevillano están en riesgo de diluirse en un cosmopolitismo, del que nos contagiamos principalmente a través de los modernos medios de difusión.

Termina haciendo un llamamiento a los poetas, para que elaboren un Código de las esencias sevillanas, que haga posible su defensa"(LARASBL, 1951-1971: fol. $36 r)$.

Si bien es evidente que no puede hablarse de una manipulación ni tergiversación del discurso, tampoco parece que pueda negarse una selección consciente de aquellas partes o ideas que ella había incluido en su conferencia, ignorado sus aspectos más renovadores y realzando los tintes conservadores. Según indican las actas, no se leyó a continuación ningún discurso de contestación, y con el fin de la conferencia se clausuró el acto. ${ }^{11}$ Estas actas serían leídas y aprobadas, como de costumbre, en la siguiente sesión ordinaria del 17 de mayo. ${ }^{12}$

Habitualmente, a la entrada de un miembro en la Academia sevillana le seguía una reseña de media o entera columna en la sección «Vida académica y cultural» del $A B C$ sevillano, donde se destacaba el título y el contenido del discurso, la contestación al mismo, y el público que asistió al evento (muy escuetamente la mayoría de las veces). Sin embargo, la única alusión a este acontecimiento que aparece en el diario no se refiere en concreto al acto de lectura del discurso, sino a la junta ordinaria que se celebró seis días después del mismo y donde, como se ha dicho antes, se leyeron y aprobaron las actas correspondientes (ABC de Sevilla, 22-05-1957: 23). Es más, el texto de la nota de prensa y el que aparece en las actas de la junta ordinaria es el mismo, con la diferencia de que en el diario no se incluye los párrafos que en las actas relatan la lectura del correo por parte de la junta. Es decir, la entrada de María Laffitte en la Academia no se difunde a través de los medios sino de forma indirecta, incluida en un artículo más general, lo que contrasta con la relevancia que este diario otorga a los demás eventos de esta naturaleza en la misma época. Sirva como ejemplo lo publicado al respecto de la siguiente entrada de un nuevo miembro en la institución.

11 «Al término de su brillante conferencia, la Condesa de Campo Alange, fue muy aplaudida y felicitada por todos, entregándosele un hermoso ramo de flores. Con ello terminó la sesión, la que que como secretario $1^{\circ}$, certifico» (LARASBL, 1951-1971: fol. 36r).

12 «Rezadas las preces de Reglamento, el Secretario $1^{\circ}$ que suscribe, dio lectura a las actas de [...] la sesión pública, solemne y extraordinaria en la que disertó sobre el tema "Aquella y esta Sevilla", la Excma. Sra. Da María de los Reyes Laffitte y Pérez del Pulgar, Condesa de Campo de Alange, las cuales fueron aprobadas por unanimidad» (LARASBL, 1951-1971: fol. 37r). 
El 16 de marzo de 1958 ingresa como académico de número Manuel Beca Mateo, personalidad de peso en la Sevilla de entonces por haber estado al frente del Ateneo hasta aquel mismo año. Las actas siguen la fórmula habitual, recogiendo el título del discurso («Alfonso XIII ante la Historia: Tres decisiones reales»), una breve descripción de su contenido, y la contestación que se le hizo, en este caso, de parte de Blázquez Bores (LARASBL, 1951-1971: fol. 51r). El mismo día por la mañana, precediendo el acto, aparece otra vez en la sección «Vida académica y cultural» del ABC la noticia de la «recepción académica de Don Manuel Beca Mateo» (ABC de Sevilla, 16-03-1958: 69). Sin embargo, lejos de quedarse en este breve párrafo de nueve líneas, el diario publica el martes 18 de marzo una crónica de página y media del acto, que incluye un retrato del académico entrante, y otra breve reseña a parte del «cock-tail» que ofreció él mismo en su domicilio (ABC de Sevilla, 18- 03-1958: 27-28).

Los ejemplos de María Laffitte y Manuel Beca son, evidentemente, casos opuestos en importancia para la institución y de relevancia en los medios, dado el lugar que ocupaban cada uno como miembro de la Academia (correspondiente y numerario), y la influencia y prestigio con que contaban en la ciudad. No obstante, resulta llamativa la ausencia de alusiones a Laffitte en los 29 años que fue académica. Ni siquiera su fallecimiento aparece citado en las actas o en el boletín oficial. En aquellas, de haber constado, hubiera sido el la junta ordinaria siguiente a su fallecimiento. Si este se produjo el 6 de julio de 1986, la junta correspondiente en la que previsiblemente hubiera sido nombrada sería la del 10 de octubre de 1986. Paradójicamente, en el documento solo se cita que «... se tomaron, entre otros acuerdos, los de hacer llegar el pésame de la Corporación a los Sres. Académicos que han sufrido pérdidas familiares y también a la familia del profesor Carande, Académico de Honor» (LARASBL, 1951-1971: fol. 264r). Ni rastro del fallecimiento de la escritora. Tampoco la citan en la sección «Relación de las juntas celebradas por la Real Academia de Buenas Letras durante el curso 1986-1987» del Minervae Baeticae, donde vuelve a recogerse el caso de Ramón Carande. Sí aparece, sin embargo, la referencia de una misa: «el 7 de Noviembre se celebró en el Convento de San José de las Madres Carmelitas la Misa en sufragio de los académicos fallecidos que ordena el artículo 32 de nuestra reglamento [sic]» (Minervae Beticae, 1987: 155). Probablemente, fuera esta misa «reglamentaria» en la que se le rendiría homenaje póstumo. No se debe pensar que la ausencia de referencias es compartida por todos los académicos correspondientes, ya que a muchos de ellos se les celebró misa particular y su fallecimiento apareció recogido en las actas. Visto todo esto, no parece imprudente afirmar que la relación entre la institución sevillana y la escritora fue prácticamente nula, tal vez a causa la distancia geográfica y de la lejanía intelectual que mantenían entre ellas.

Volviendo a lo dicho en las actas sobre la intervención de Laffitte, es necesario destacar un dato que, por inusual, cobra relevancia. Después de las presentaciones de los académicos y demás asistentes de prestigio, dice así: «Un numeroso público, en el que destacaba la presencia de distinguidas damas, ocupaba totalmente el salón 
de actos» (LARASBL, 1951-1971: fol. 35v). Este enunciado no responde a ninguna fórmula protocolaria ni se encuentra en las actas pertenecientes a las décadas de los años cincuenta hasta los ochenta. No es difícil deducir su causa. Después de la publicación de La batalla de los sexos, en muchos periódicos nacionales había aparecido reseñado para bien o para mal el libro, del que por entonces ya se habían hecho dos ediciones (LARASBL, 1951-1971: 148 r). Probablemente, su fama como escritora precediera a la llegada de Laffitte a Sevilla. Esto explicaría la asistencia de estas «distinguidas damas» al acto.

Siguiendo siempre la información que proporcionan las actas, la congregación femenina en el discurso de María Laffitte marca un hito sobre la presencia femenina en los eventos académicos, ya que los documentos no recogen esta asistencia de mujeres hasta el 26 de marzo de 1963, con la toma de posesión de una plaza de académico por parte de José Acedo Castilla. Aparece en las actas de este acto la fórmula «El amplio salón estaba totalmente ocupado por muy selecta concurrencia, en la que abundaban las Señoras» (LARASBL, 1951-1971: fol. 148r). Efectivamente, se puede observar el incremento de mujeres asistentes a los actos de la Academia a partir ya de inicios de la siguiente década de los sesenta. Para la entrada en la institución de Carlos García Fernández el 19 de enero de 1964, las actas vuelven a señalar que «el amplio salón estaba totalmente ocupado por muy selecta concurrencia en la que figuraban las Señoras y las Señoritas» (LARASBL, 1951-1971: fol. 160r). Este último modelo se repetirá en prácticamente todas las actas que se levanten de los actos públicos de la Academia hasta finales de los años ochenta. ${ }^{13}$ La rigidez de la formula no permite analizar los posibles matices o perfiles del público. Sin embargo, parece claro que si se hubo de recurrir a este enunciado fue ante la necesidad de dejar constancia de un fenómeno que se estaba produciendo. No es extraño que durante estas décadas haya un incremento de mujeres asistentes a actos de cierta altura intelectual, dado el aumento lento y progresivo de mujeres que comienzan a participar en otros espacios intelectuales y culturales (las aulas universitarias, por ejemplo). Este enunciado recogido en las actas académicas ilustra el incipiente fenómeno de la incorporación de la mujer al mundo cultural español a partir de finales de los años sesenta y sobre todo de los setenta.

Pocas mujeres tuvieron la oportunidad de frecuentar los círculos eruditos de la España franquista. Menos aún fueron las que divergieron de las opiniones que en ellos se vertían, o las que se atrevieron a manifestar públicamente su desafección respecto a las ideas que expresaban sus integrantes. Laffitte fue en este sentido excepcional. Aceptó en 1944 con mucho agrado formar parte, como única mujer, de la Academia

13 Véase la entrada de Lorenzo Polaino Ortega (19/04/1964), 1951-1971, fol. 166v.; el premio del Certamen Sánchez Bezoya (13/12/1964), 1951-1971, fol. 174v.; la entrada de Francisco Aguilar Piñal (13/06/2014)1951-1971, fol. 183v; la entrada de José Antonio Calderón Quijano (12/10/1970) 1951-1971, fol. 282v; la entrada de Juan Collantes de Terán y Collantes de Terán (26/05/1973) 19711988, fol. 29r; la conferencia de Miguel Ángel Asturias (22/03/1974) 1971-1988, fol. 40v. 
Breve de Eugenio d'Ors, al que siempre se refirió, a pesar de sus desavenencias, como «maestro». Admitió en 1957 con satisfacción ser miembro correspondiente de la Academia Sevillana de Buenas Letras, a pesar de que su talante intelectual, en los últimos años cincuenta difiriera bastante de la línea general de pensamiento de los ilustres sevillanos. Le ofrecieron además en 1962 el cargo de vicepresidenta del Ateneo de Madrid, el cual aceptó y mantuvo durante pocos años hasta que dimitió cansada de discordias. En sus memorias, confiesa que solo pudo ver cumplidos sus deseos de trabajo colectivo a través de un grupo que, lejos de tener naturaleza académica o institucional, fue ilegal (solicitaron permiso oficial para reunirse y se lo denegaron), aconfesional y apolítico: el Seminario de Estudios Sociológicos de la Mujer. ${ }^{14}$

Los proyectos y las ideas de Laffitte enlazan y probablemente echan sus raíces en un ambiente intelectual polarizado entre posturas que, aunque cercanas al régimen, discrepan en los requerimientos y en las expectativas que mantienen respecto a él. No hay que olvidar que, aparte de considerarse «discípula» de D’Ors, mantuvo a la par una estrecha relación de admiración hacia José Ortega y Gasset (en cuya editorial, Revista de Occidente, publicaría varios libros) y fue gran amiga del «ubicuo» Gregorio Marañón. Este mosaico de personalidades entre los que Laffitte se movió, junto con las pinceladas de su pensamiento arriba citadas, dibuja el complicado perfil de alguien que se osciló entre la proximidad a los círculos más afines al fascismo, como el de D'Ors, y la cercanía, física e intelectual, a la que se ha llamado «tradición liberal», entendida como aquella que, partiendo de los casos de Baroja, Azorín, Ortega, Marañón y Pérez de Ayala, entre otros, había aprendido a «articular bajo un Estado de derecho las libertades individuales y las diferencias más hondas de pensamiento» (Gracia, 2004). A esta tradición liberal, subsumida al régimen, es a la que Laffitte se sintió presumiblemente más cercana. Aún empeñándose en dejar bien claro que tenía «pánico a todo lo que rozase la política», tanto sus proyectos como las ideas que dejó por escrito, su compromiso con las nuevas formas de arte (no apoyadas por el Régimen), con la mejora de la situación social de la mujer y con la divulgación de las ideas evolucionistas, la posicionan en una actitud activamente política cercana, si no a la tradición liberal, sí al cuestionamiento de la dictadura que actuaba como opresor de aquella.

Así pues, es bien comprensible que ya en los ochenta y en plena madurez Laffitte afirmara que nunca había sido un ideal para ella pertenecer a ninguna academia, y que mucho menos le había quitado el sueño. En el caso de la institución sevillana, parece que tampoco les inquietó excesivamente la ausencia de María Laffitte, que no participó en ninguna junta, ordinaria o extraordinaria, durante la veintena de años que fue académica. En una maniobra de selección, el mensaje principal de

14 Fundado en 1960, estuvo encabezado por María e integrado por Consuelo de la Gándara, Elena Catena, María y Pura Salas Larrazábal, Concepción Borreguero Sierra, María Jiménez Bermejo y Lilí Álvarez. 
su discurso de entrada a la Academia Sevillana fue edulcorado, rebajando mucho el contenido aperturista que le animaba y restándole, por tanto, la novedad que suponía. No obstante, y sin restar un ápice de valor al texto, no es esta la obra más transgresora de la escritora. La secreta guerra de los sexos y De Altamira a Hollywood profundizan en muchos aspectos que el discurso, si nombre, es de modo superficial. Sin embargo, todas estas obras ha tenido una suerte similar, ya que solo se han analizado de modo fragmentario, intermitente, y poco riguroso (o como el caso del último libro citado, ni siquiera se han estudiado). Sin que haya una única causa para explicarlo, parece que el progresismo y la originalidad mal entendida de sus contenidos puede ser una de las justificaciones. Por este motivo, el paso de María Laffitte por la Academia Sevillana de Buenas Letras puede ilustrar con claridad cómo fue la distante relación que mantuvo con muchas instituciones de su tiempo a las cuales perteneció, y puede ejemplificar también la sutil resistencia que sus ideas encontraron para colarse y cuestionar el discurso oficial, en unos tiempo en los que, por supuesto, lo oficial era un terreno difícilmente expuesto a la disputa.

\section{BIBLIOGRAFÍA}

Cuénot, C. (1966). Teilhard de Chardin, Barcelona: Labor.

De la Vega Viguera, E. (1998). Historia resumida de la Real Academia Sevillana de Buenas Letras (1751-1997). Sevilla: Gráficas San Antonio.

Gracia, J. (2004). La resistencia silenciosa. Fascismo y cultura en España. Barcelona: Anagrama.

Laffitte y Pérez del Pulgar, M. (1957 Aquella y esta Sevilla. Conferencia leída ante la Real Academia de Buenas Letras. Madrid: Estades Artes Gráficas.

Laffitte y Pérez del Pulgar, M. (1953). De Altamira a Hollywood, metamorfosis del arte. Madrid: Revista de Occidente.

Laffitte y Pérez del Pulgar, M. (1961). La mujer como mito y como ser humano. Madrid: Taurus.

Laffitte y Pérez del Pulgar, M. (1964). La mujer en España. Cien años de su historia. Madrid: Aguilar.

Laffitte y Pérez del Pulgar, M. (1983). Mi atardecer entre dos mundos. Barcelona: Planeta.

Laffitte y Pérez del Pulgar, M. (1990). Mi niñez y su mundo. Madrid: Castalia. Primera edición: 1953, Revista de Occidente.

Laffitte y Pérez del Pulgar, M. (2003). La secreta guerra de los sexos. Madrid: Horas y Horas. Primera edición: 1948, Revista de Occidente.

Makinistian, A. (2004). Desarrollo histórico de las ideas y teorías evolucionistas. Zaragoza: Prensas Universitarias de Zaragoza. 
Marzo, J. L. (2006). Arte moderno y franquismo. Los orígenes de la vanguardia y de la política artística en España. Alojado en la plataforma www.soymenos.net.

Masanet, L. (1998). La autobiografía femenina contemporánea. Madrid: Fundamentos.

Medina Doménech, R. M. (2013) Ciencia y sabiduría del amor. Una historia cultural del Franquismo (1940-1960). Madrid: Iberoamericana.

Minervae Baeticae: boletín de la Real Academia Sevillana de Buenas Letras (1987). Sevilla: Secretariado de publicaciones de la Universidad de Sevilla.

Nielfa Cristóbal, G. (2002). La difusión en España del Segundo Sexo de Simone de Beauvoir. Arenal, 9, no 1, p. 151-162.

Nielfa Cristóbal, G. (2002). Pensamiento y Feminismo en la España de 1961. María Campo Alange: La Mujer Como Mito y Como Ser Humano. Arenal, 9, nº 1, 185196.

Pelayo, F. (2009). Darwin en España. Las controversias sobre la teoría de la evolución en la comunidad científica española. Apuntes de Ciencia y Tecnología, nº 33, p. 27-33.

Pérez de Laborda, A. (2001). La filosofía de Pierre Teilhard de Chardin: la emergencia de un pensamiento transfigurado. Madrid: Encuentro Ediciones.

Pineda Novo, D. (2007). La poesía popular andaluza en el Siglo XX. Vida y obra de Juan Rodríguez Mateo. Sevilla: Ateneo de Sevilla.

\section{FUENTES}

Libros de Actas de la Real Academia Sevillana de Buenas Letras. 1951-1971, y 19711988.

ABC de Sevilla, 22 de mayo de 1957, p. 23.

ABC de Sevilla, 16 de marzo de 1958, p. 69.

ABC de Sevilla, 18 de marzo de 1958, pp. 27-28.

AM: Ateneo de Madrid. Memoria 1962-1967. 